JPE (Jurnal Pendidikan Edutama) Vol. 7 No. 2 Juli 2020

P-ISSN : 2339-2258 (Print) E-ISSN: 2548-821X (Online)

http://ejurnal.ikippgribojonegoro.ac.id/index.php/JPE

\title{
PERAN APLIKASI SCHOOLOGY DALAM PEMBELAJARAN FLIPPED CLASSROOM PADA MATERI TEKS ANEKDOT
}

\author{
Rani Jayanti ${ }^{1}$, Suesthi Rahayuningsih ${ }^{2}$ \\ ${ }^{1}$ Pendidikan Bahasa dan Sastra Indonesia, Universitas Islam Majapahit \\ email: ranijayanti_12@yahoo.com \\ ${ }^{2}$ Pendidikan Matematika, Universitas Islam Majapahit \\ email: esthiachmad@gmail.com
}

\begin{abstract}
Schoology Apps is a part of Learning Management System (LMS) that makes it easy for teachers and students to interact wherever and whenever in learning anecdote text. Anecdote text begins to be taught to high school students, especially the tenthgrade students in Curriculum 2013. The purpose of this study is to investigate the role of schoology apps to learn anecdote text in flipped classroom. This study is a library research that starts from 1) choosing a topic, 2) exploring information, 3) setting the focus of study, 4) preparing data sources, 5) preparing data presentation, and 6) preparing reports. This data is secondary data from national and international journals, Indonesian and international books. The data collection method uses the documentation method. Data validation technique uses data triangulation techniques. It is analyzed using a content analysis method. The results show that anecdote text materials are compiled into schoology apps and integrated with a flipped classroom model that refers to Bergmann \& Sams theory. The conclusion of this study is that the schoology apps plays an important role in the flipped classroom, it can be seen from the use of schoology apps for students at home. When they are at home or anywhere in the sense of not being in the classroom learning, they can access the materials of anecdote text first. In addition, they can have direct discussion before the classroom learning begins through the schoology apps.
\end{abstract}

Keyword: schoology apps, flipped classroom, anecdote text

Abstrak: Aplikasi schoology merupakan bagian dari LMS yang mempermudah pendidik dan peserta didik berinterasi dimanapun dan kapanpun dalam mempelajari teks anekdot. Teks anekdot mulai diajarkan pada siswa menengah atas, khususnya kelas 10 kurikulum 2013. Tujuan penelitin ini adalah ingin mengetahui peran aplikasi schoology dalam pembelajaran flipped classroom pada materi teks anekdot. Penelitian ini merupakan penelitian studi pustaka (library research) dengan prosedur penelitian dimulai dari, 1) memilih topik, 2) mengeskplorasi informasi, 3) menetapkan fokus penelitian, 4) menyiapkan sumber data, 5) menyiapkan penyajian data, dan 6) menyusun laporan. Data penelitian ini adalah data sekunder yang bersumber dari jurnal nasional, jurnal internasional, buku terbitan Indonesia dan luar negeri. Metode pengumpulan data menggunakan metode dokumentasi. Teknik validasi data menggunakan teknik triangulasi data. Data dianalisis menggunakan content analysis. Hasil penelitian menunjukkan bahwa materi-materi teks anekdot disusun ke dalam aplikasi schoology dan selanjutnya diintergrasikan dengan model pembelajaran flipped classroom yang mengacu pada teori Bergmann \& Sams. Simpulan penelitian ini adalah aplikasi schoology sangat berperan penting dalam model pembelajaran flipped classroom, peran tersebut dapat dilihat dari penggunaan aplikasi schoology bagi siswa ketika sedang di rumah. Ketika sedang di rumah atau di manapun dalam artian tidak sedang dalam pembelajaran di kelas, siswa dapat mengakses materi teks anekdot terlebih dahulu, selain itu, siswa dapat berdiskusi secara langsung sebelum pembelajaran dimulai melalui aplikasi schoology.

Kata kunci: aplikasi schoology, flipped classroom, teks anekdot 


\section{PENDAHULUAN}

Anekdot merupakan satu materi pada kurikulum K13. Materi ini tertuang pada KI 3 yang berbunyi memahami, menerapkan, menganalisis pengetahuan faktual, konseptual, prosedural berdasarkan rasa ingin tahunya tentang ilmu pengetahuan, teknologi, seni, budaya, dan humaniora dengan wawasan kemanusiaan, kebangsaan, kenegaraan, dan beradaban terkait penyebab fenomena dan kejadian, serta menerapkan pengetahuan prosedural pada bidang kajian yang spesifik sesuai dengan bakat dan minatnya untuk memecahkan masalah, dengan kompetensi dasar 3.5 mengevaluasi teks anekdot dari aspek makna tersurat dan 3.6 menganalisis struktur dan kebahasaan teks anekdot.

Teks anekdot mulai diajarkan pada siswa menengah atas, khususnya kelas 10 . Fatimah (2013) menambahkan bahwa teks anekdot baru disampaikan secara tersurat pada kurikulum 2013 melalui mata pelajaran bahasa Indonesia. Teks anekdot menurut Suherli, dkk. (2017) merupakan cerita singkat yang lucu dan mengesankan. Cerita pada teks anekdot menurut Triyani dkk. (2018) bersumber dari kisah faktual dengan tokoh nyata yang terkenal. Teks anekdot menurut Kosasih (2017) mengandung unsur humor dan kritik.

Struktur teks anekdot diawali dengan adanya abstraksi, orientasi, krisis, reaksi, dan koda (Suherli, dkk., 2017). Adapun penjelasaanya adalah sebagai berikut, 1) abstraksi dapat diartikan sebagai bentuk pendahuluan yang berisi gambaran umum isi teks, 2) orientasi adalah penyebab bagian krisis muncul, 3) krisis/komplikasi adalah inti peristiwa yang mengandung kekonyolan, 4) reaksi adalah tanggapan dari bagian krisis yang mengandung unsur celaan atau bahan tertawaan, 5) koda adalah bagian penutup/simpulan, di dalam koda berisi persetujuan, komentar atau penjelasan. Koda ditandai dengan kata demikianlah, akhirnya, atau seperti itu, koda sifatnya opsional.

Berdasarkan hasil wawancara dengan guru matapelajaran bahasa Indonesia, Materi anekdot juga diajarkan di MA Assulaimaniyah Mojoagung Jombang pada semester 1. Materi ini diajarkan oleh guru dengan mengunakan metode ceramah dan media gambar seadanya. Dengan model pembelajaran yang konfensional inilah, peneliti menemukan masalah utama ketika siswa mengikuti pembelajaran teks anekdot, pertama, siswa belum bisa menyampaikan ide dengan benar sesuai struktur teks anekdot, kedua, siswa sulit berkomunikasi dengan guru atau siswa yang lain saat sedang di rumah, ketiga, metode konvensional kurang menarik diterapkan pada era saat ini.

\begin{tabular}{|c|c|}
\hline $\begin{array}{l}\text { Ketiga } \\
\text { menjadikan }\end{array}$ & $\begin{array}{l}\text { temuan } \\
\text { dasar }\end{array}$ \\
\hline
\end{tabular}
menerapkan model pembelajaran flipped classroom. Model pembelajaran terbalik atau sering disebut sebagai model pembelajaran flipped classroom sudah banyak sekali diterapkan di negara-nagar maju, terlebih di negara Indonesia. Banyak peneliti sering menerapkan model ini dan tidak jarang memodifikasi atau mengkolaborasi metode ini. Seperti yang pernah dilakukan oleh Hasanudin \& Fitrianingsih (2018b) bahwa model pembelajaran flipped classroom yang dikolaborasi dengan aplikasi Screencast-OMatic mampu meningkatkan verbal linguistik (kemamupuan berbahasa) mahasiswa. Ada tujuh indikator verballinguistic intelligence yang dimiliki mahasiswa pada saat mengikuti matakuliah keterampilan membaca (Hasanudin \& Fitrianingsih, 2020).

Model flipped Classroom dipopulerkan pertama kali oleh Bergman dan Aaron pada tahun 2007, semenjak kemunculan metode ini, banyak sekali peneliti mengujicobakan metode ini dalam pembelajaran. Secara garis besar model pembelajaran Flipped Classroom itu membalik metode pembelajaran di kelas, dibalik di sini artinya, siswa harus membaca/belajar terlebih dahulu di rumah, sehingga ketika di kelas pengajar tidak lagi menjelaskan/mengajar siswa tersebut (Hasanudin \& Fitrianingsih, 2019).

Model Flipped Classroom menurut Damayanti dan Sutami (2016) membalik atau menukar konsep yang selama ini dilakukan di dalam kelas diubah menjadi di luar kelas atau sebaliknya. Pada awalnya siswa di dalam kelas mendengarkan 
penjelasan guru kemudian pulang ke rumah untuk mengerjakan soal, membaca matri, menonton video pembelajaran. Pada pertemuan selanjutnya siswa saling berdiskusi, berbagi pengetahuan, menyelesaikan permasalahan dengan dibantu siswa lain atau guru. Guru membantu siswa dengan proyek yang menantang dengan cara memberikan control belajar yang lebih besar.

Langkah-langkah menerapkan metode flipped classroom adalah, 1) mengajarkan kepada siswa bagaimana cara mengunjungi, mengamati, dan berinteraksi melalui video pembelajaran, 2) Mengarahkan siswa agar melihat materi pembelajaran yang ada dalam file video, 3) Guru menyuruh peserta didik untuk mengajukan pertanyaan ketika proses pembelajaran berlangsung, 4) Guru memberikan tugas individu atau kelompok, 5) Guru senantiasa mengarahkan kepada peserta didik untuk saling membantu, 6) Guru memberikan simpulan terhadap pembelajaran yang telah dilakukan Menurut (Bergmann dan Sams dalam Yulietri, 2015)

Penelitian Hasanudin \& Fitrianingsih (2018a) menjelaskan bahwa penerapan flipped classroom dapat membantu siswa menemukan kebutuhan belajarnya. Penelitian yang dilakukan oleh Alamri (2019) menyebutkan bahwa pembelajaran flipped classroom pada pendidikan formal berhasil diterapkan dan pada umumnya menunjukkan peningkatan prestasi akademik dan kepuasan siswa. Model pembelajaran Flipped Classroom menurut Johnson (2013) adalah bentuk strategi guru dalam meminimalkan perintah/instruksi dan memaksimalkan interaksi antar siswa. Strategi ini butuh teknologi sebagai penyedia materi tambahan secara online.

Salah satu teknologi yang dapat diakses secara online yaitu dengan menggunakan aplikasi schoology. Aplikasi ini merupakan bagian dari LMS yang mempermudah pendidik dan peserta didik berinterasi dimanapun dan kapanpun, terlebih mempermudah dalam menyampaikan materi, menjawab quiz, dan mengumpulkan tugas. Penggunaan aplikasi schoology pernah diterapkan oleh Hidayat, Wardono, \& Rusilowati (2019) dapat meningkatkan kemampuan literasi matematika siswa.

Platform schoology dikembangankan oleh Jeremy Friedman, Ryan Hwan dan tim Trinidad. Platform ini ditawarkan gratis kepada semua pendidik. Aplikasi yang merupakan bagian dari LMS (learning management system) dapat diakses melalui perangkat berbasis iOS, android, dan kindle. LMS menurut Sicat (2015) dapat mengembangkan kompetensi siswa.

Schoology merupakan media yang sangat menjanjikan dalam menjawab tantangan pada saat ini dan masa depan terutama masalah pengajaran abad 21 (Biswas, 2013). Scholoogy berbentuk website yang memadukan antara e-learning dengan media sosial (Aminoto \& Pathoni, 2014). Aplikasi ini mudah digunakan dan konsepnya seperti pembelajaran di dalam kelas (Putri, Jampel, \& Suartama, 2014). Adapun tampilan awal aplikasi schoology adalah seperti berikut.

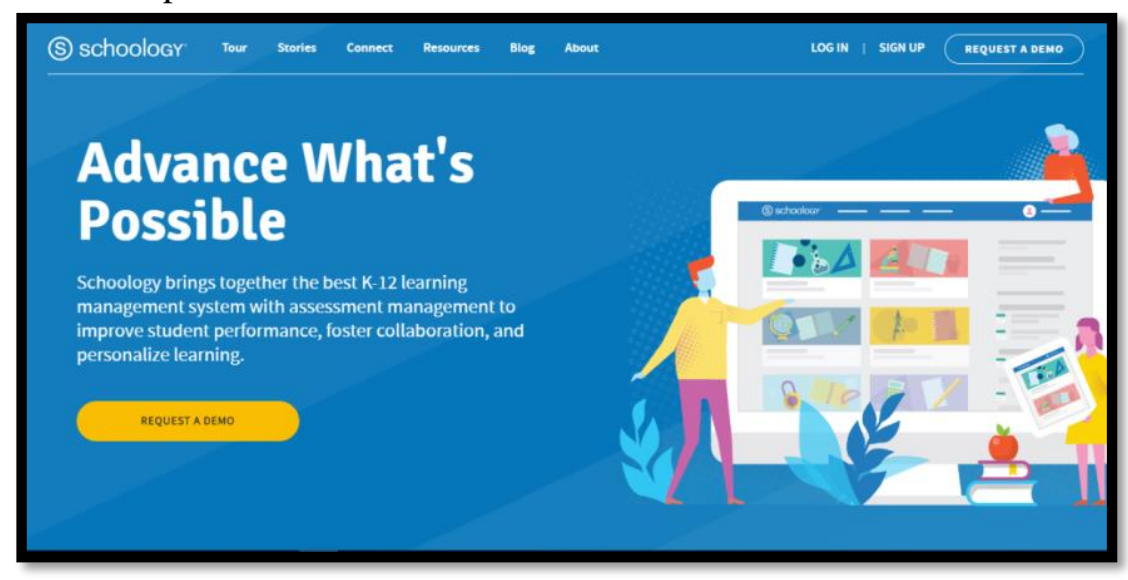

Gambar 1. Tampilan awal aplikasi schoology 
Penelitian Tsaniyah, Ayu, \& Pratiwi (2019) menyebutkan bahwa siswa yang diajar dengan menggunakan aplikasi schoology memiliki kemampuan mengatur belajar secara efektif dan selalu bisa bersaing untuk memperoleh hasil yang paling baik. Hasil penelitian Resty, Muhardjito, \& Mufti (2019) menyebutkan bahwa model pembelajaran discovery learning berbantuan schoology memberikan hasil kemampuan berpikir kritis siswa lebih baik dibandingkan dengan penerapan model pembelajaran discovery learning tanpa menggunakan aplikasi schoology. Pada penelitian ini, peneliti ingin mengkolaborasikan aplikasi schoology pada pembelajaran flipped classroom sehingga peneliti dapat mengetahui bagaimana teks anekdot yang dibuat oleh siswa.

Hasil penelitian Aulia dan Umar (2019) menunjukkan bahwa adanya korelasi pemahaman tentang struktur dan ciri kebahasaan dengan kemampuan menulis teks anekdot siswa. Penelitian Said dan Pratama (2019) membuktikan bahwa adanya peningkatan hasil kemampuan menulis anekdot ketika diajar dengan menggunakan strategi genius learning. Pada penelitian ini, peneliti ingin membuktikan hasil teks anekdot siswa ketika diajar dengan menggunaka model pembelajaran flipped classroom yang memanfaatkan aplikasi schoology

Tujuan khusus pada penelitian ini adalah bagaimanakah peran aplikasi schoology dalam pembelajaran flipped classroom? Kolaborasi ini penting dilakukan mengingat saat ini memasuki era industry 4.0 yang mengharuskan semua serba digital, termasuk ketika siswa dalam memahami teks anekdot, siswa dapat belajar melalui aplikasi schoology dimanapun, dengan siapapun, dan kapanpun dengan mudah. Dengan demikian pembelajaran lebih mudah dan menyenangkan buat siswa.

\section{METODE PENELITIAN}

Penelitian ini merupakan penelitian studi pustaka (library research). Penelitian studi pustaka menurut Sugiyono (2012) merupakan kajian teoretis, referensi, dan literatur tentang budaya dan nilai pada situasi sosial. Penelitian ini menurut Sarwono dalam Nurotusholihah \& Ramdani (2017) berguna untuk mendapatkan landasan teori. Zed (2008) menambahkan bahwa batasan pada penelitian studi pustaka adalah pada analisis referensi kepustakaan bukan riset lapangan.

\section{Prosedur Penelitian}

Prosedur penelitian kepustakaan ini digunakan untuk menyusun konsep metode flipped classroom pada materi teks anekdot dengan berbantukan aplikasi schoology yang akan diterapkan pada siswa kelas $\mathrm{X}$ MA Assulaimaniyah Mojoagung Jombang. Adapun langkah-langkahnya mengadopsi dari teori Kuhlthau (2002) yaitu, 1) memilih topik, 2) mengeskplorasi informasi, 3) menetapkan fokus penelitian, 4) menyiapkan sumber data, 5) menyiapkan penyajian data, dan 6) menyusun laporan

\section{Sumber Data}

Data penelitian ini berupa data sekunder yang bersumber dari jurnal nasional, jurnal internasional, buku terbitan Indonesia dan luar negeri tentang metode flipped classroom, media aplikasi schoology, dan teks anekdot. Referensireferensi ini disusun berdasarkan prosedur penelitian sehingga menghasilkan materimateri tentang teks anekdot. Materi ini kemudian diinputkan dalam aplikasi schoology. Setelah aplikasi schoology terisi dan layak digunakan, selanjutnya peneliti melakukan pembelajaran di kelas dengan menerapkan konsep pembelajaran flipped classroom.

\section{Metode pengumpulan data}

Penelitian ini menggunakan metode dokumentasi. Data yang sudah dicari dan dikumpulkan dari berbagai literatur dikumpulkan menjadi satu kesatuan dokumen untuk menjawab permasalahan yang sudah dirumuskan.

\section{Teknik validasi data}

Teknik triangulasi digunakan dalam memvalidasi data. Triangulasi memiliki empat tipe, yaitu triangulasi data, peneliti, metode, dan teori (Denzin dalam Hasanudin, Fitrianingsih, \& Saddhono, 
2019a). Triangulasi data yang digunakan adalah triangulasi teori. Triangulasi teori pada penelitian ini dilakukan dengan cara mengkompilasikan, menyarikan, dan mensintesiskan teori-teori yang ada pada jurnal nasional, jurnal internasional, buku terbitan Indonesia dan luar negeri sesuai dengan topik yang akan dibahas.

\section{Teknik analisis data}

Penelitian ini menggunakan content analysis dalam menganalisis data. Metode content analysis memiliki tiga alur, yaitu 1) reduksi data, 2) penyajian data, dan 3) penarikan simpulan (Miles \& Huberman, 2017). Pada reduksi data, peneliti mensortir referensi yang sesuai dengan topik permasalahan. Pada bagian menyajian data, peneliti menyajian referensi-referensi yang berkaitkan dengan topik permasalahan, pada langkah terakhir, peneliti membuat sebuah simpulan bahwa sumber referensi yang telah disajikan mampu memberikan jawaban atas topik yang dibahas, sehingga menjadi satu-kesatuan topik bahasan.

\section{HASIL DAN PEMBAHASAN}

Pada bagian ini, tidak terlepas dari peran aplikasi schoology pada model pembelajaran flipped classroom untuk materi teks anekdot. Materi-materi teks anekdot disusun ke dalam aplikasi schoology dan selanjutnya diintergrasikan dengan model pembelajaran flipped classroom yang mengacu pada teori Bergmann \& Sams (2012: 77), yaitu 1) hari pertama pada model pembelajaran flipped classroom, 2) menginformasikan model pembelajaran flipped classroom, 3) menjelaskan kepada siswa cara mengakses video, 4) meminta siswa untuk membuat pertanyaan, 5) Mengarahkan siswa untuk saling membantu, 6) membuat sistem penilaian, 7) Siswa mengecek pembelajaran yang lebih luas terhadap tugas tugas yang lebih rumit.

Ketujuh langkah ini, selanjutnya dikolaborasi dengan menggunakan media aplikasi schoology. Adapun bentuk peran aplikasi schoology pada pembelajaran kolaborasi ini dapat dijelaskan sebagai berikut.

\section{Peran aplikasi schoology pada hari pertama model pembelajaran flipped classroom}

Hari pertama penerapan pembelajaran flipped classroom, peneliti menyiapkan 1) materi, materi yang disusun peneliti adalah materi teks anekdot. Materi ini disusun dalam bentuk file PPT menggunakan microsoft powerpoint atau ada juga yang disusun dalam bentuk video, 2) membuat tes, tes dibuat peneliti dalam bentuk pilihan ganda dan akan ditampilkan pada saat pertemuan awal dan akhir, 3) memberikan tugas, peneliti membuat kolom tugas pada aplikasi untuk mempermudah siswa dalam mengumpulkan tugas.

Pada hari pertama, ketiga menu itu merupakan komponen wajib yang harus ada pada aplikasi schoology, selain itu, peneliti juga menyediakan menu kolom komentar dan profil peneliti/pengajar agar siswa lebih mudah dalam menyampaikan keluhan pada saat di luar kelas. Adapun tampilan kelas yang sudah dibuat oleh peneliti dapat dilihat pada gambar berikut. 


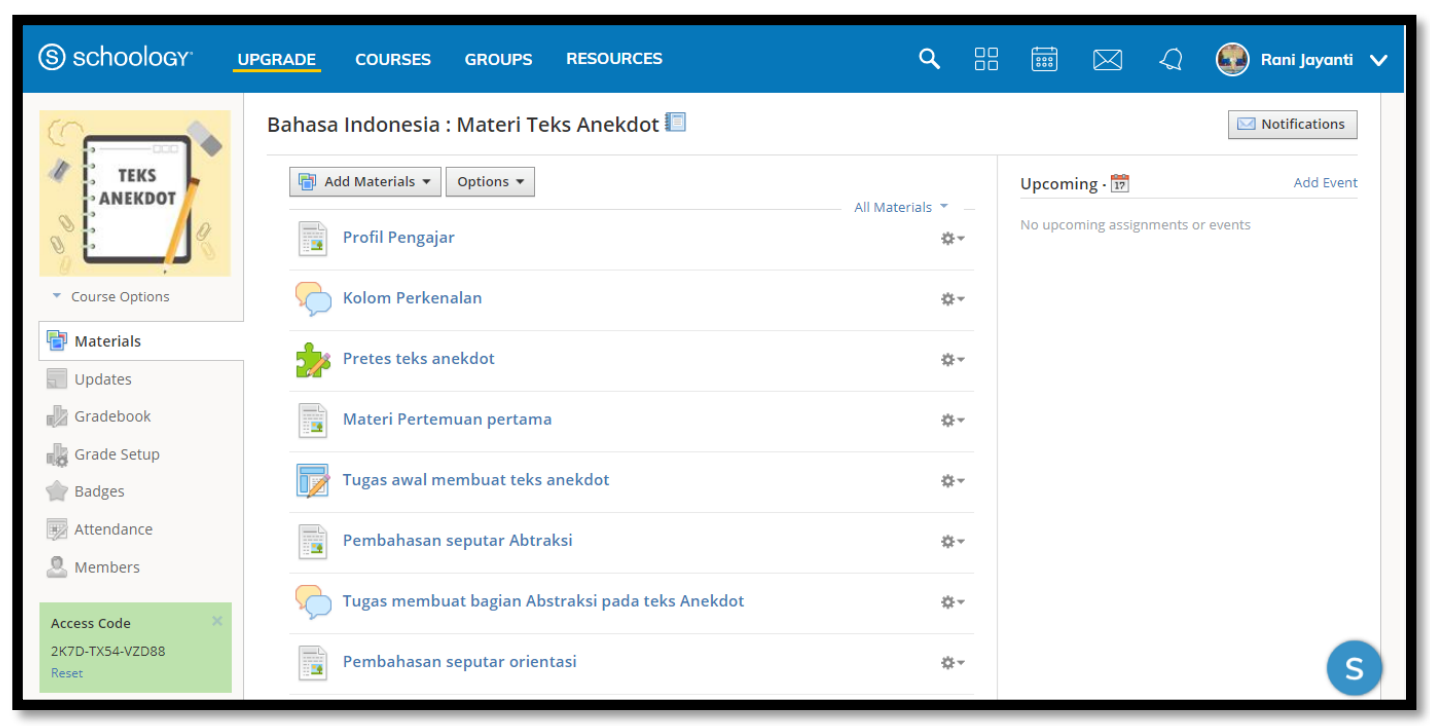

Gambar 2. Materi teks anekdot pada aplikasi schoology

Menginformasikan model pembelajaran flipped classroom serta peran aplikasi schoology

Pada langkah ini, peneliti menjelaskan peran aplikasi schoology serta bagaimana aplikasi ini digunakan pada pembelajaran flipped classroom. Peneliti memberikan gambaran kolaborasi media dan metode ini kepada seluruh siswa, mulai dari apa saja yang harus dilakukan oleh siswa pada saat di rumah dan bagaimana pembelajaran di dalam kelas berlangsung.

\section{Menjelaskan kepada siswa cara bergabung di aplikasi schoology}

Guru menginstruksikan kepada siswa cara bergabung dalam kelas daring melalui aplikasi schoology dengan mengikuti langkah berikut, 1) siswa harus mengakses laman https://www.schoology.com/ melalui smartphone masing-masing, 2) kemudian pilih menu sign up kemudian pilih student, 3) masukkan access code (kode akses) berikut 2K7D-TX54-VZD88 untuk bergabung pada kelas Bahasa Indonesia: Materi Teks Anekdot seperti pada gambar berikut,

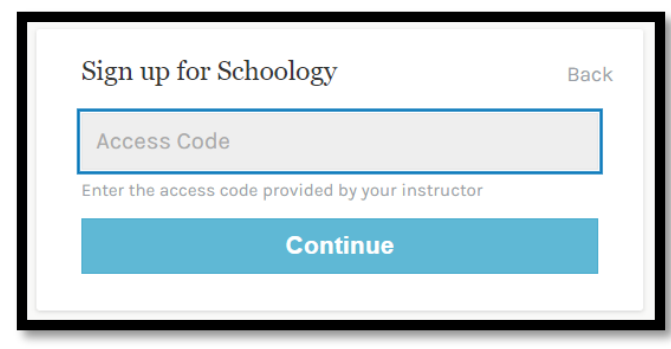

Gambar 3. Sign up ke schoology

4) isilah biodata sesuai identitas masing-masing siswa kemudian centang kotak dialog register dan klik register seperti pada gambar berikut,

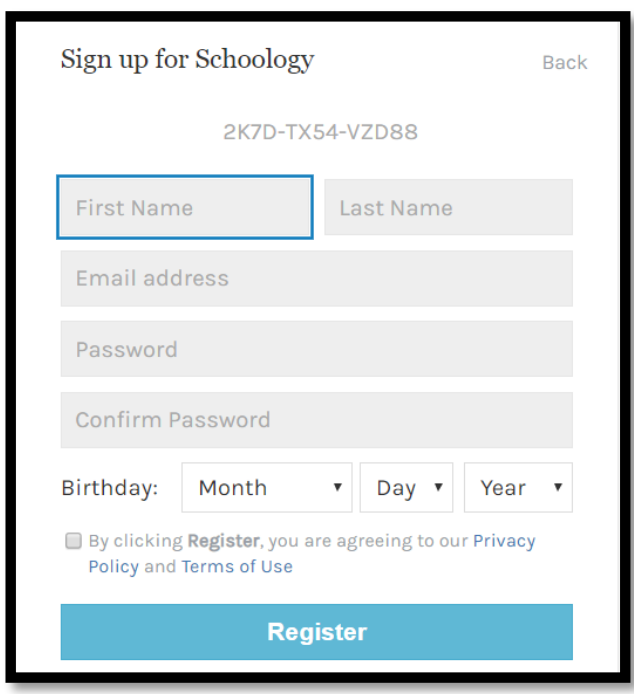

Gambar 4. Tampilan mengisi biodata 
5) isilah identitas kelas, kota, provinsi, dan negara tempat siswa belajar, hingga muncul tulisan sukses mendaftar, 6) carilah menu courses pada bagian menu paling atas, jika tidak ada bisa klik my courses untuk melihat kelas yang sudah dibuat oleh peneliti.

\section{Meminta siswa untuk membuat pertanyaan pada aplikasi schoology}

Pada langkah ini merupakan bentuk asimilasi. Pada tahapan ini, guru memberikan informasi kepada siswa untuk membuat pertanyaan terhadap setiap materi yang belum dikuasai, pertanyan ini dimasukkan pada kolom komentar yang sudah disediakan oleh peneliti pada aplikasi schoology. Di sini peneliti hanya mengamati setiap pertanyaan yang masuk dan tidak memberikan penjelasan atau memberikan instruksi langsung. Selain membuat pertanyaan, siswa juga harus mempelajari meteri-materi yang sudah diunggah pada aplikasi ini. Bentuk asimilasi ini dilakukan siswa pada saat di luar jam pembelajaran teks anekdot.

\section{Mengarahkan siswa untuk saling membantu}

Pada langkah ini, peneliti dan siswa berada di dalam satu kelas. Siswa menyampaikan soal yang sudah ditulis pada aplikasi schoology. Peneliti memberikan kesempatan yang sama kepada seluruh siswa. Peneliti memastikan pertanyaan yang diberikan oleh siswa sudah ada di aplikasi dan sudah sesuai. Jika sudah sesuai, peneliti memberikan kesempatan kepada siswa yang lain untuk menjawab dan memberikan argumen. Peneliti hanya sebagai fasilitator dan tidak memberikan penjelasan materi tentang anekdot. Peneliti memberikan bimbingan agar semua siswa benar-benar mengerti apa yang disampaikan oleh temannya. Peneliti dan siswa berinteraksi secara aktif untuk menganalisis, mengevaluasi, serta membuat sebuah konsep baru. Hal yang paling mendasar pada langkah ini adalah siswa benar-benar dapat berpikir kritis serta berpikir kreatif dalam memecahkan suatu permasalah yang dihadapi oleh temannya. Pada bagian ini, peneliti harus memahmi konsep dasar model pembelajaran flipped classroom. Konsep ini adalah FLIP. FLIP berarti (Flexible Environment, Learning Culture, Intentional Content, Professional Teacher).

\section{Membuat sistem penilaian pada aplikasi schoology}

Pada bagian ini, peneliti membuat sistem penilaian. Sistem penilaian dapat dilakukan sebelum pembelajaran teks anekdot, saat pembelajaran, atau setelah pembelajran berlangsung. Penilaian dapat berupa tugas atau soal tes yang sudah disusun pada aplikasi schoology. Siswa dapat mengunjungi aplikasi schoology dan memilih menu quiz. Quiz yang sudah dibuat dapat dilihat pada gambar berikut,

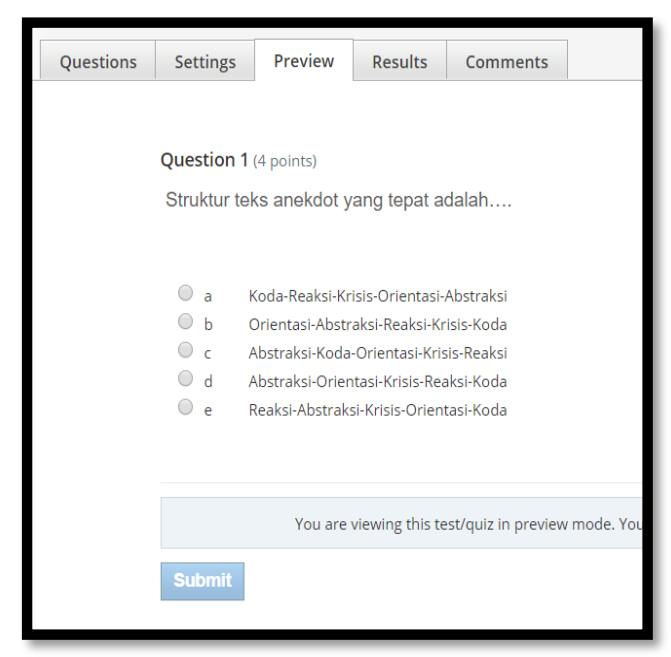

Gambar 5. Quiz tentang teks anekdot

Siswa mengecek pembelajaran yang lebih luas terhadap tugas-tugas yang lebih rumit melalui aplikasi schoology

Pada bagian ini, peneliti mengajak siswa untuk mencari referensi lain tentang teks anekdot. Siswa dapat mencari dengan bantuan google scholar atau melihat di menu youtube. Setelah peneliti merasa siswa sudah cukup memiliki pengetahuan yang luas tentang teks anekdot. Selanjutnya, peneliti pemberikan kesempatan untuk menjawab pertanyaan yang sudah pada aplikasi schoology. Bentuk pertanyaan tersebut untuk mengukur keterampilan siswa dalam menulis teks anekdot. Adapun tugas tersebut dapat dilihat pada gambar berikut ini. 


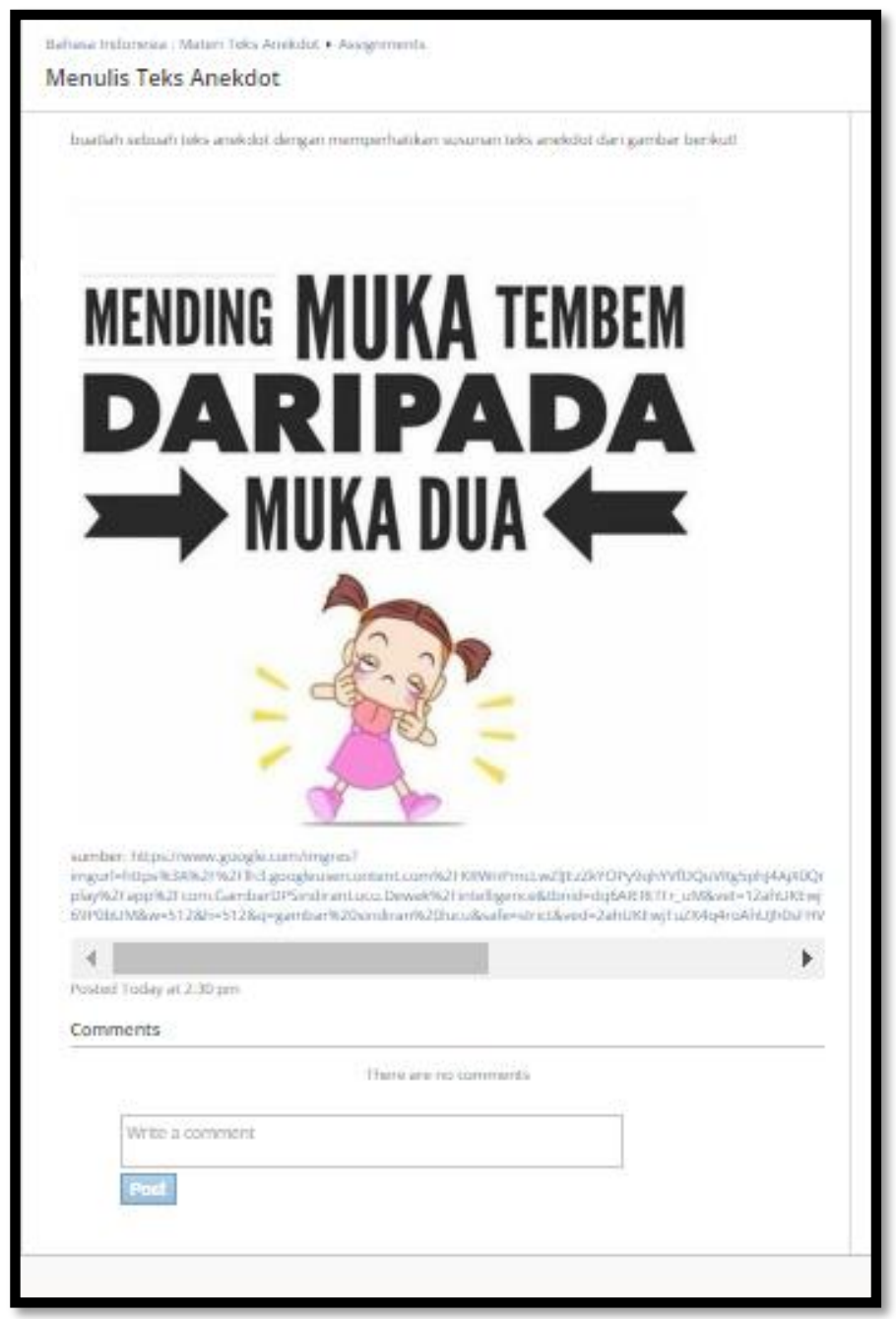

Gambar 6. Tugas membuat teks anekdot dari gambar meme

Peran aplikasi schoology pada pembelajaran flipped classroom sangatlah besar. Hal ini didukung oleh kemudahan dalam mengoperasikan aplikasi schoology. Hasil penelitian Fitrianningsih, dkk (2020) menunjukkan bahwa guru SMP dapat menjalankan aplikasi schoology, guru-guru dapat mendaftar, mengisi materi, membuat quiz dan membagikan kode kelas ke siswa. Penelitian Tolino, Jumadi, dan Astuti (2020) menunjukkan bahwa aplikasi schoology dalam pembelajaran problem based learning model aided mampu mengembangkan keterampilan komunikasi visual siswa. Aplikasi schoology pernah diterapkan oleh Saddhono, Hasanudin, Fitrianingsih (2019) untuk mengetahui kemampuan berpikir kreatif mahasiswa. Agar peran aplikasi schoology pada pembelajaran flipped classroom dapat diterapkan pada pembelajaran kurikulum 2013 maka Hasanudin, Fitrianingsih, Saddhono, (2019b) menambahkan bahwa metode pembelajaran flipped classroom harus terintegrasi dengan salah satu pendekatan yang digunakan pada kurikulum 2013.

\section{SIMPULAN}

Aplikasi schoology sangat berperan penting dalam model pembelajaran flipped classroom, peran tersebut dapat dilihat dari penggunaan aplikasi schoology bagi siswa ketika sedang di rumah. Ketika sedang di rumah atau di manapun dalam artian tidak sedang dalam pembelajaran di kelas, siswa dapat mengakses materi teks anekdot terlebih dahulu, selain itu, siswa dapat berdiskusi secara langsung sebelum 
pembelajaran dimulai melalui aplikasi schoology. Siswa harus lebih aktif di luar kelas mempelajari materi teks anekdot. Pengunaan aplikasi schoology pada model pembelajaran flipped classroom menerapkan tujuh langkah pembelajaran. Inilah esensi penting dalam model pembelajaran terbalik (flipped classroom).

\section{UCAPAN TERIMA KASIH}

Penulis mengucapkan terima kasih kepada Deputi Bidang Penguatan Riset dan Pengembangan Kementerian Riset dan Teknologi/Badan Riset dan Inovasi Nasional dengan nomor surat B/87/E3/RA.00/2020 tanggal 28 Januari 2020 telah memberikan dana penelitian melalui hibah PDP (Penelitian Dosen Pemula).

\section{DAFTAR RUJUKAN}

Alamri, M. M. (2019) 'Students' academic achievement performance and satisfaction in a flipped classroom in Saudi Arabia'. International. Journal Technology Enhanced Learning, 11(1), 103-119. Retrieved from https://www.inderscienceonline.com /doi/abs/10.1504/IJTEL.2019.096786

Aminoto, T. \& Pathoni, H. (2014). Penerapan media e-learning berbasis schoology untuk meningkatkan aktivitas dan hasil belajar materi usaha dan energi di Kelas XI SMA N 10 Kota Jambi. Jurnal Sainmatika, 8(1), 13-29.

Aulia, G. A. \& Umar, A. (2019). Hubungan pemahaman struktur dan ciri kebahasaan dengan kemampuan menulis teks anekdot siswa kelas $\mathrm{X}$ SMA Negeri 4 Medan. Bahastra Jurnal Pendidikan Bahasa dan Sastra Indonenesia, 3(2), 73-77.

Bergmann, J., \& Sams, A. (2012). Flip your classroom: Reach every student in every class every day. Washington, DC: Internal Society for Technology in Education.
Biswas, S. (2013) "Schoology-supported classroom management: a curriculum review," Northwest Journal of Teacher Education, 11(2), 1-10. Retrieved from https://pdxscholar.library.pdx.edu/nw jte/vol11/iss $2 / 12$

Damayanti, H. N. dan Sutama. (2016). Efektivitas flipped classroom terhadap sikap dan keterampilan belajar matematika di SMK. Jurnal Managemen Pendidikan. 11 (2): 2-8.

Fatimah, N. (2013). Teks anekdot sebagai sarana pengembangan kompetensi bahasa dan karakter siswa. Jurnal Varidika, 26(1), 1-10.

Fitrianingsih, A., dkk. (2020). Mengelola kelas online dengan aplikasi schoology. Jurnal PKM: Pengabdian kepada Masyarakat, 3(1), 1-11. Retrieved from https://journal.lppmunindra.ac.id/ind ex.php/pkm/article/view/5212.

Hasanudin, C., \& Fitrianingsih, A. (2018a). Flipped classroom using screencasto-matic apps in teaching reading skill in indonesian language. International Journal of Pedagogy and Teacher Education (IJPTE), 2, 151-158. Retrieved from https://jurnal.uns.ac.id/ijpte/article/vi $\underline{\text { ew/25356 }}$

Hasanudin, C., \& Fitrianingsih, A. (2020). Verbal linguistic intelligence of the first-year students of Indonesian education program: A case in reading subject. European Journal of Educational Research, 9(1), 117-128. https://doi.org/10.12973/eujer.9.1.117.

Hasanudin, C., dan Fitrianingsih, A. (2018b). The implementation of flipped classroom using screencastomatic to improve students' verbal linguistic intelligence. International Journal of Engineering \& Technology, 7(4), 435-439. 
https://doi.org/10.14419/ijet.v7i4.15. 23602.

Hasanudin, C., Fitrianigsih, A. (2019). Analisis gaya belajar mahasiswa pada pembelajaran flipped classroom. Jurnal Pendidikan Edutama, 6(1), 31-36. https://doi.org/10.30734/jpe.v6i1.364

Hasanudin, C., Fitrianingsih, A., \& Saddhono, K. (2019a). How is the student's negotiation text in collaborative learning of flipped classroom and a CyberLink power director media apps. Ingénierie des Systèmes d'Information, 24(6), 559567.

https://doi.org/10.18280/isi.240601.

Hasanudin, C., Fitrianingsih, A., Saddhono, K. (2019b). The use of wondershare filmora version 7.8.9 media apps in flipped classroom teaching. Review of Computer Engineering Studies, 6(3),

51-55. https://doi.org/10.18280/rces.060301.

Hidayat, Y. N., Wardono, \& Rusilowati, A. (2019). Analisis kemampuan literasi matematika ditinjau dari metakognisi siswa dalam pembelajaran synectics berbantuan schoology. PRISMA, Prosiding Seminar Nasional Matematika, 2, 911-916.

Johnson, G. B. (2013). Student perceptions of the flipped classroom. Columbia: The University of British Columbia.

Kosasih. (2014). Jenis-jenis teks. Bandung, Indonesia: Yrama Widya.

Miles, M. B. dan Huberman, A. M. (2007). Analisis data kualitatif: Buku sumber tentang metode-metode baru. Terjemahan Tjetjep Rohendi Rohidi. Jakarta, Indonesia: Universitas Indonesia Press.

Putri, M, A, Ni Wyn., Jampel, N., \& Suartama, I. K. (2014). Pengembangan e-learning berbasis schoology pada mata pelajaran IPA kelas VIII di SMP Negeri 1 Sririt. Journal Edutech Universitas Pendidikan Ganesha, 2(1), 1-11.

Resty, Z. N., Muhardjito, \& Mufti, N. (2019). Discovery learning berbantuan schoology: Upaya peningkatan kemampuan berpikir kritis. Jurnal Pendidikan: Teori, Penelitian, dan Pengembangan, 4(2), 267-273. Retrieved from http://journal.um.ac.id/index.php/jptp p/article/view/12040/5700

Saddhono, K., Hasanudin, C., Fitrianingsih, A. (2019). The ability to think creatively on SSCS using schoology Apps, how is the student's language metacognitive awareness? Ingénierie des Systèmes d'Information, 24(4), 367-375.

https://doi.org/10.18280/isi.240402.

Said, I. I. N. \& Pratama, R. Y. (2019). Analisis Kesulitan Belajar Teks Anekdot dengan Strategi Genus Learning. Parole Jurnal Pendidikan Bahasa dan Sastra Indonesia, 2(2), 145-152. Retrived from https://journal.ikipsiliwangi.ac.id/ind ex.php/parole/article/view/2174/pdf

Sicat, A. S. (2015). Enhancing College Student's Proficiency in Business Writing via Schoology. International Journal of Education and Research, 3(1), 159-178.

Suherli, Suryaman, M., Septiaji, A., \& Istiqomah. (2017). Bahasa Indonesia: Buku Guru. Edisi Revisi. Kementerian Pendidikan dan Kebudayaan: Jakarta.

Tolino, F., Jumadi, dan Astuti, D. P. (2020). Students' verbal communication skills using ehandout aided Schoology with problem-based learning model on lup-optic topics. Journal of Physics: Conference Series, 1440, 1- 
$6 . \quad$ htpps://doi:10.1088/1742$\underline{6596 / 1440 / 1 / 012033 .}$.

Triyani, N., Romdon, S., \& Ismayani, M. (2018). Penerapan Metode Discovery Learning pada Pembelajaran Menulis Teks Anekdot. Parole (Jurnal Pendidikan Bahasa dan Sastra Indonesia), 1(5), 713-720.

Tsaniyah, S. F., Ayu, H. D., \& Pratiwi, H. Y. (2019). Pengaruh Model Blended Learning Menggunakan Schoology terhadap Prestasi Belajar ditinjau dari Kemandirian Belajar Siswa. RAINSTEK Jurnal Terapan Sains \& Teknologi, 1(1), 71-77. Retrieved from http://ejournal.unikama.ac.id/index.p hp/jtst/article/view/3236

Yulietri, F. (2015). Pengaruh Model Flipped Classroom dan Discovery Learning terhadap Prestasi Belajar Matematika Ditinjau dari Kemandirian Siswa Kelas VII SMP Negeri Di Kabupaten Sragen. Tesis. Surakarta: Universitas Negeri Surakarta. 
36 JURNAL PENDIDIKAN EDUTAMA, Vol.7, No.2 Juli 2020 